\title{
The Child Soldiers Project: Employing a Project-Based Learning and Teaching Curriculum
}

\author{
Oana Maria Cusen \\ Ritsumeikan University, Kyoto, Japan
}

\begin{abstract}
In recent years, project-based learning and teaching (PBLT) has received a great deal of attention from educators around the world and is now establishing its place in the language learning classroom, as a means of providing a more realistic setting for learning. However, PBLT can be difficult to implement in the Asian context due to the focus on more traditional teaching methods which emphasize exams. This paper introduces the Child Soldiers Project created for a Japanese high school classroom by focusing on the steps involved in the curriculum design. Using various concepts drawn from curriculum design, content-based learning, and learner autonomy, the rationale for each step is discussed. Finally, the Child Soldiers Project is placed within a PBLT framework, and a case made for its efficacy.
\end{abstract}

Although not a new approach to language learning, project-based learning and teaching (PBLT) has only received recognition as an effective educational pedagogy in the last twenty years (Beckett, 2006). A unified, concise definition is difficult, and it is generally described in terms of characteristics (Beckett, 2006; Stoller, 2006). For the purposes of this paper, the following eight characteristics were considered, based on Stoller (2006): PBLT should 1) maintain a focus on the project content, 2) consist of a series of manageable tasks, progressing in complexity and structured to provide opportunities to recycle knowledge and skills, 3) allow students to make some of their own choices throughout the project, 4) stimulate students' interest, 5) afford each student the opportunity to contribute equally and to use their individual skills during group work, 6) ensure all students take responsibility and are held accountable for their work, 7) include activities which focus on form, as well as skills practice throughout the project, 8) provide students with continuous feedback and opportunities for reflection.

This paper adds to the body of work on PBLT by introducing the Child Soldiers Project, implemented in a Japanese high school class. It demonstrates the successful implementation of a project in a language classroom, based on PBLT principles. The steps outlined maximize the development of students' skills. Specific language learning targets are not set; instead, overall fluency and general academic skills are developed.

Following a brief literature review and a description of the classroom context, the framework for the project design is introduced and each step is presented in detail. Finally, the paper discusses how the project satisfied the conditions for successful PBLT.

Language Education in Asia, 2013, 4(2), 163-174. http://dx.doi.org/10.5746/LEiA/13/V4/I2/A06/Cusen 


\section{Literature Review}

As the ESL and EFL fields moved away from traditional teaching methodologies such as the grammar translation method and towards student-centered approaches, PBLT was put forth as a way of creating a classroom environment in which students could be more involved in the process of learning (Hedge, 1993). Although research into PBLT began with anecdotal evidence from a variety of teaching contexts, attempts at theorizing PBLT have also been made (Stoller, 2006).

This paper argues that PBLT is particularly relevant to language learning and teaching in Asia, due to the current trend of moving away from traditional teacher-centered instruction and towards communicative, learner-centered language education (Muller, Herder, Adamson, \& Brown, 2012). PBLT provides one possible framework for this shift and is already attracting attention from researchers and practitioners across Asia: in Japan (Kobayashi, 2006), China (Guo, 2006), Thailand (Boondee, Kidrakarn, \& Sa-Ngiamvibool, 2011), Korea (Lee \& Lim, 2012), and Turkey (Kemaloglu, 2010), among others.

Through the description of the successful implementation of a project in a Japanese high school, this paper attempts to show how the PBLT approach can involve students in the learning process, both inside and outside the classroom.

\section{Classroom Context}

The project was created for the $11^{\text {th }}$ grade in a Japanese high school and implemented over five months, spanning the second and third trimesters of the academic year. It was the primary focus of a 45-minute English class held three times a week.

Two-thirds of the school's students have spent one year or more studying abroad, while the remaining students have studied in Japan only. Students are streamed by English language ability, based on in-house tests, interviews with the English faculty and the duration of overseas study.

Three $11^{\text {th }}$ grade groups totaling 69 students aged 16 or 17 participated in the project. The students' L1 is Japanese and the L2 throughout this project was English. The three groups comprised students at the intermediate level (approximate TOEIC scores between 500 and 750). They had lived in English-speaking countries for less than three years or in non-English speaking countries or had reached intermediate English level while studying exclusively in Japan. Their language level allowed them to work with authentic English materials and to use the target language for most of the tasks outlined in this paper.

Most of the project was done in groups of three, randomly changed for each task to allow students to get to know each other better and feel comfortable working with everyone in the class.

\section{Steps in Creating the PBLT Curriculum}

The structure of a project can be roughly separated into two parts, content input and content output. The two stages represent the comprehensible input and meaningful output considered essential for effective language learning (Stoller, 2006). Within a project, both stages must be carefully planned and followed by a reflection stage to maximize the outcomes for the students. The following subsections introduce the seven steps of the framework used for creating and implementing the Child Soldiers Project (Table 1). The rationale for each step is discussed, 
based on theoretical concepts drawn from curriculum design, content-based teaching, and learner autonomy.

Table 1

Project Curriculum Design

\begin{tabular}{|l|l|}
\hline \multicolumn{1}{|c|}{ Stage } & \multicolumn{1}{c}{ Steps } \\
\hline \multirow{4}{*}{ Content input stage } & 1. Selecting a theme \\
\cline { 2 - 2 } & 2. Selecting content materials \\
\cline { 2 - 2 } & 3. Designing and sequencing tasks for content input \\
\hline \multirow{4}{*}{ Content output stage } & 4. Establishing the final outcome for the project \\
\cline { 2 - 2 } & 5. Structuring the process for creating the final product \\
\cline { 2 - 2 } & 6. Exhibiting the final product \\
\hline Reflection stage & 7. Reflecting on the entire project \\
\hline
\end{tabular}

\section{Selecting a Theme}

Needs analysis is an integral part of sound curriculum design (Richards, 2001). When selecting a theme for the Child Soldiers Project, the content needs of the students were carefully considered. In this particular high school, all $11^{\text {th }}$ grade students learn about the effects of World War II on Japan. The theme of child soldiers (children forced to join armed conflicts as soldiers) was considered appropriate because it presents a different aspect of war that Japanese students are usually not exposed to; additionally, the students were relatively close in age to the child soldiers they would learn about. Moreover, this was a chance to expose students to a global education topic (Cates \& Jacobs, 2006) giving students the opportunity to learn about the lives of other children around the world.

\section{Selecting Content Materials}

One of the most important characteristics of PBLT is that it is content driven (Stoller, 2006), making the selection of appropriate content extremely important. All the materials chosen were authentic, providing advantages such as improving learner motivation by providing real sociocultural information and real language (Richards, 2001). The materials were not graded in any way.

Three types of authentic materials were chosen: a novel, A Long Way Gone: Memoirs of a Boy Soldier (Beah, 2007), a movie, Blood Diamond, (Amato \& Zwick, 2006), and a presentation by a United Nations volunteer who had worked in Sierra Leone in 2005. The contents of the novel were not graded for the students. The movie was played with English subtitles to facilitate comprehension to a certain extent. The presentation and subsequent question and answer session were also carried out in English.

The novel. The main means of content input for the project is a partly fictionalized account of Beah's experiences as a child soldier in Sierra Leone. Beah initially tried to escape the conflict between the government and the RUF (Revolutionary United Front), but was eventually caught by government forces and forced to become a child soldier. He was later rescued by UNICEF and placed into a rehabilitation center before immigrating to the United States, where he was adopted by an American family.

The movie. Blood Diamond, released by Warner Bros. in 2006, was chosen to supplement the book for content input. The movie is set during the civil war in Sierra Leone and includes many 
scenes based on eyewitness accounts. The movie was incorporated into the project to provide a more realistic picture of events in Sierra Leone.

The presentation. A United Nations volunteer gave a presentation on her experiences of working in Sierra Leone approximately four years after the end of the civil war. She worked closely with local volunteers and thus was able to give a detailed firsthand account of the country and its people. The presentation helped to make the civil war and its effects on the population of Sierra Leone real for the students, providing a bridge between the fictionalized accounts in the book and movie and the factual research that students later completed during the content output stage.

\section{Designing and Sequencing the Tasks for Content Input}

Various tasks were developed and carefully sequenced to foster students' understanding of the content material, as well as the development of critical thinking skills. Willis \& Willis (2007) argued for the importance of planning the task sequence to allow students adequate time to prepare the tasks to be carried out in class. Ellis (2003) also pointed out that sequencing tasks is essential "to facilitate maximum learning" (p. 220). This allowed students to build subsequent skills and knowledge on previously gained ones.

Table 2 summarizes the tasks designed for the three types of content materials chosen. Detailed explanations of the gallery walk, discussion circles, and focus on form tasks are included in Appendix A.

\section{Table 2}

\section{Content Input Tasks and Their Purposes}

\begin{tabular}{|c|c|c|c|}
\hline Material & Tasks & Task purpose & Language \\
\hline \multirow{5}{*}{ Novel } & Gallery walk & Initial content review & L2 \\
\hline & Discussion circles & Deeper content analysis & L2 \\
\hline & Imagining the ending & Prediction of content & L2 \\
\hline & $\begin{array}{l}\text { Summarizing } \\
\text { Putting story events in order }\end{array}$ & Content review & L2 \\
\hline & $\begin{array}{l}\text { Vocabulary } \\
\text { Mini grammar lessons }\end{array}$ & Focus on form & $\mathrm{L} 2+\mathrm{L} 1$ \\
\hline \multirow[b]{2}{*}{ Movie } & Answering comprehension questions & Initial content review & L2 \\
\hline & $\begin{array}{l}\text { Vocabulary } \\
\text { Mini grammar lessons }\end{array}$ & Focus on form & $\mathrm{L} 2+\mathrm{L} 1$ \\
\hline \multirow{3}{*}{ Presentation } & Research & Prediction of content & $\mathrm{L} 2+\mathrm{L} 1$ \\
\hline & Creating questions for speaker & Prediction of content & L2 \\
\hline & Question and answer session with speaker & Deeper content analysis & L2 \\
\hline
\end{tabular}

The tasks related to the novel were sequenced in a natural progression. Students completed initial content review tasks immediately after reading each section of the book before moving onto deeper analysis tasks, such as discussion circles, to develop critical thinking skills. Before reading the last chapters of the book, prediction tasks allowed students to build logically on existing knowledge to make educated guesses about the end of the story. Finally, review tasks after each section ensured consolidation of content learning. The main language medium for these tasks was L2, with only very occasional use of L1 as students clarified task instructions for 
each other.

The movie was used as support material; thus, the tasks were not as extensive as those for the book. Students engaged in initial content reviews and discussed comprehension questions with the help of a worksheet. L2 was used primarily for these tasks.

For the book and the movie, focus on form tasks were implemented to ensure vocabulary acquisition and practice of grammatical structures necessary for the successful completion of the content tasks. For these tasks, both L1 and L2 were used. The teacher presented and explained the target forms in L2 to the entire class and provided further explanations in L1 as necessary. Groups were also given the chance to confirm their understanding in their L1.

Students prepared for the presentation by learning about the current situation in Sierra Leone as opposed to the image depicted in the novel and movie. This allowed them to predict the content of the presentation and to prepare questions. The 20-minute presentation was followed by a question and answer session (both in English), which allowed students to reflect further on the presentation content.

\section{Establishing the Final Outcome for the Project}

The final product for the project was set by the teacher and designed to foster speaking and presentation skills. Groups prepared poster presentations on a topic of their choice related to child soldiers. Giving students the choice of topic aligns with PBLT principles as it empowers students to take responsibility for their own learning (Stoller, 2006). It also has numerous other benefits: increased autonomy and motivation, increased student learning, and improved classroom behavior, as any apathy previously demonstrated essentially disappears (Passe, 1996).

\section{Structuring the Process for Creating the Final Product}

The process for creating the final product was loosely based on the writing process (Nation, 2009). The steps used were:

1. Brainstorming and choosing a topic

2. Research

3. Outline

4. Feedback on outline

5. Poster draft

6. Feedback on poster draft

7. Final poster

8. Practice presentation

First, groups of students brainstormed topics related to the general theme of child soldiers and chose the topic of most interest. Students then researched their chosen topic and produced a poster outline. The teacher provided extensive feedback on these outlines to facilitate a better connection of ideas. Next, students worked on the poster drafts, with mock-up posters also receiving teacher feedback prior to the creation of the final posters. The last step was practicing the presentations, during which they also received teacher feedback on delivery. Additionally, peer feedback was incorporated throughout the entire process, with all students responsible for reviewing the work of each member in the group.

In this stage, L1 played a much more extensive role than in the content input stage. To allow for cognitive and academic transfer from L1 (Cummins, 2007), the use of L1 was not 
discouraged; thus, students used Japanese for brainstorming, outlining, feedback, and some of their research. All written work, presentation practice, and final presentations used English exclusively.

\section{Exhibiting the Final Product}

A carousel format was used for the poster presentations, with each group presenting three times to small audience groups. This type of simultaneous interaction (Kagan, 1994) allows students more interaction time with their peers as compared to the more traditional format in which one group presents in front of the entire class. Furthermore, giving the presentation three times affords students the chance to improve their performance and language use through task repetition (Lynch \& Maclean, 2001).

\section{Reflecting on the Entire Project}

The final stage, the reflection stage, is essential for the consolidation of the acquired language (Stoller, 2006). Here, students performed two reflective tasks. First, they discussed their performance throughout the entire project in groups, focusing on the process of creating the final presentations. Students presented their conclusions to the entire class in a teacher-led class discussion. In the group discussions, both L1 and L2 were used, but the teacher used the L2 for the follow-up class discussion. Finally, students completed a worksheet focused on reflections on the entire project; this was done in English. Appendix B includes a detailed analysis of the students' feedback on the Child Soldiers Project.

\section{Situating the Child Soldiers Project Within PBLT Parameters}

The conditions for successful PBLT below have been adapted from Stoller (2006). Following each condition, the author addresses how that particular condition was met during the design or execution of the Child Soldiers Project.

\section{Focus on the Project Content}

Content was the main drive behind this project: in the content input stage through authentic materials and in the content output stage when students generated content based on research from authentic materials.

\section{Progressively Complex Tasks and Knowledge and Skills Recycling}

Throughout the project, tasks were sequenced to ensure students progressed smoothly from one task to the next. In the content input stage, for example, students recalled the content they had read before discussing it in depth, used the insights gained to predict subsequent events, and then reviewed the content to ensure retention.

\section{Student Choices}

The content output stage gave students the freedom to choose any topic related to the issue of child soldiers. Groups chose topics such as the daily lives of child soldiers, girls as child soldiers, international organizations helping child soldiers, and the problem of drugs being used to control child soldiers.

\section{Stimulation of Interest}

Through reading about Beah's experiences, students became emotionally invested, in part because of the proximity in age between them and the child soldiers in the novel and movie. Furthermore, they understood the importance of educating others on this issue, which increased their motivation in preparing engaging presentations. The project's effect was not temporary, as 
anecdotal evidence showed that many students chose to enroll in further social studies classes dealing with the issue of minorities around the world.

\section{Opportunities to Contribute}

The varied nature of the tasks allowed each student to contribute in ways they were most comfortable with, in turn increasing their motivation to improve skills they lacked in. In one group, for example, a student whose reading and writing skills were slightly lower managed to contribute not only his higher levels of fluency and confidence in public speaking, but also his personal experiences of living in South Africa for several years.

\section{Student Accountability}

From the beginning of the project, the teacher made clear that all students were expected to contribute equally to group work. However, it was peer pressure ensured that each member completed assignments. Throughout the entire content output stage of the project, the teacher only assigned the major goals, such as the completion of the poster draft. It was left to the groups to divide the work and to monitor progress.

\section{Focus on Form Activities and Skills Practice}

Focus on form tasks targeting both vocabulary and grammatical aspects were incorporated throughout the project. The teacher also gave feedback on the language use in posters and presentation speeches.

\section{Continuous Feedback and Opportunities for Reflection}

The students' performance was evaluated after each task, and the teacher gave frequent individual, group and class feedback on language use and skills development. The feedback was both summative in the form of grades, and formative to foster student development.

\section{Conclusion}

Recognizing the challenges of incorporating PBLT in foreign language classrooms in Asia, this paper adds to the growing literature on PBLT in the region by reporting on its successful implementation in a Japanese high school classroom. Through a series of tasks, students learned content while developing academic and English language skills. They were also given choices of content and process, allowing them to take responsibility for their learning and to become independent learners.

Future research should examine the relationship between project work and learner autonomy in more detail to establish the efficacy of PBLT in fostering learner autonomy in Asia. To that end, student performance and reflections need further examination as a means of evaluating the PBLT curriculum. Furthermore, proficiency in listening, speaking, reading, writing, and fluency should be measured before, during, and after the end of a project to establish the effect of PBLT on language acquisition.

\section{Author Note}

Oana Maria Cusen, Department of Science and Engineering, Ritsumeikan University, Kyoto, Japan.

Correspondence concerning this article should be addressed to Oana Maria Cusen, Department of Science and Engineering, Ritsumeikan University, Biwako-Kusatsu Campus, 1-1-1 NojiHigashi, Kusatsu, Shiga 525-8577, Japan. E-mail: oana.in.jalt@gmail.com 


\section{References}

Amato, L. (Producer), \& Zwick, E. (Director). (2006). Blood diamond [Motion picture]. United States: Warner Bros. Entertainment.

Beah, I. (2007). A long way gone: Memoirs of a boy soldier. London, England: Harper Perennial.

Beckett, G. H. (2006). Project-based second and foreign language education: Theory, research and practice. In G. H. Beckett \& P. Chamness Miller (Eds.), Project-based second and foreign language education: Past, present and future (pp. 3-16). Greenwich, CT: Information Age.

Boondee, V., Kidrakarn, P., \& Sa-Ngiamvibool, W. (2011). A learning and teaching model using project-based learning (PBL) on the web to promote cooperative learning. European Journal of Social Sciences, 21(3), 498-506.

Cates, K. A., \& Jacobs, J. (2006). Global issue projects in the English language classroom. In G. H. Beckett \& P. Chamness Miller (Eds.), Project-based second and foreign language education: Past, present and future (pp. 167-180). Greenwich, CT: Information Age.

Cummins, J. (2007). Rethinking monolingual instructional strategies in multilingual classrooms. Canadian Journal of Applied Linguistics, 10(2), 221-240.

Ellis, R. (2003). Task-based language learning and teaching. Oxford, England: Oxford University Press.

Guo, Y. (2006). Project-based English as a foreign language education in China: Perspectives and issues. In G. H. Beckett \& P. Chamness Miller (Eds.), Project-based second and foreign language education: Past, present and future (pp. 143-155). Greenwich, CT: Information Age.

Hedge, T. (1993). Project work. English Language Teaching Journal, 473), 276-277.

Kagan, S. (1994). Cooperative learning. San Clemente, CA: Kagan.

Kemaloglu, E. (2010). Project-based foreign language learning. Saarbrucken, Germany: LAP Lambert Academic.

Kobayashi, M. (2006). Second language socialization through an oral project presentation: Japanese university students' experience. In G. H. Beckett \& P. Chamness Miller (Eds.), Project-based second and foreign language education: Past, present and future (pp. 71 93). Greenwich, CT: Information Age.

Lee, H. -J., \& Lim, C. (2012). Peer evaluation in blended team project-based learning: What do students find important? Educational Technology \& Society, 15(4), 214-224.

Lynch, T., \& Maclean, J. (2001). A case of exercising: Effects of immediate task repletion on learners' performance. In M. Bygate, P. Skehan, \& M. Swain (Eds.), Researching pedagogic tasks: Second language learning, teaching and testing (pp. 141-162). Harlow, England: Longman.

Muller, T., Herder, S., Adamson, J., \& Brown, P. S. (Eds.). (2012). Innovating EFL teaching in Asia. Basingstoke: Palgrave Macmillan.

Nation, I. S. P. (2009). Teaching ESL/EFL reading and writing. New York, NY: Routledge.

Passe, J. (1996). When students choose content: A guide to increasing motivation, autonomy, and achievement. Thousand Oaks, CA: Corwin Press.

Richards, J. C. (2001). Curriculum development in language teaching. Cambridge, England: Cambridge University Press. http://dx.doi.org/10.1017/CBO9780511667220

Stoller, F. (2006). Establishing a theoretical foundation for project-based learning in second and foreign language contexts. In G. H. Beckett \& P. Chamness Miller (Eds.), Project-based second and foreign language education: Past, present and future (pp. 19-40). Greenwich, CT: Information Age.

Willis, J., \& Willis, D. (2007). Doing task-based teaching. Oxford, England: Oxford University Press. 


\section{Appendix A \\ Examples of Tasks for Content Input}

\section{Gallery Walk}

For this task, the students were put in as many groups as the number of chapters in the book section assigned for reading. For the first section of the novel for example, Chapters 1, 2, 4, and 5 were assigned for reading, so the students were put in four groups. The blackboard was section into four parts, with the title of the each chapter at the top. Groups were each assigned a section, given chalk in different colors, and instructed to write down as many things they could remember about the chapter within a time limit of two minutes. After the first two minutes, groups rotated to the next section, and the task was repeated until groups returned to their initial section of the blackboard. They were then given an additional two minutes to organize the information in their section, and then they presented this information to the class.

\begin{tabular}{|l|l|l|l|}
\hline Chapter 1 & Chapter 2 & Chapter 4 & Chapter 5 \\
\hline & & & \\
& & & \\
& & & \\
\hline
\end{tabular}

\section{Discussion Circles}

For this task, students were put in groups of three and assigned specific roles: discussion leader, summarizer, and connector. The roles were explained in detail and group members chose their own roles, for which they prepared a worksheet for homework. The actual discussion took place in the following lesson, followed by a short presentation on the conclusions of the discussion given to the entire class. Following the discussion task, groups analyzed their performance, by considering what went well during the task, what did not go very well and the reasons for it, as well as what could be improved in the next discussion circle.

Below is a detailed explanation of each role.

\begin{tabular}{|c|c|c|}
\hline Discussion leader & Summarizer & Connector \\
\hline $\begin{array}{l}\text { - prepares comprehension and } \\
\text { opinion questions on the } \\
\text { assigned reading section } \\
\text { - makes sure everyone has an } \\
\text { equal chance to speak during } \\
\text { the discussion, and presents the } \\
\text { conclusions }\end{array}$ & $\begin{array}{l}\text { - prepares a summary of the } \\
\text { assigned reading section } \\
\text { - presents the summary to the } \\
\text { group during the discussion }\end{array}$ & $\begin{array}{l}\text { - prepares a list of connections } \\
\text { between the aspects in the } \\
\text { assigned reading section and } \\
\text { the students' life in Japan } \\
\text { - presents the connection to the } \\
\text { group during discussion }\end{array}$ \\
\hline
\end{tabular}




\section{Focus on Form Tasks:}

\section{Error Correction}

This task was implemented at various points throughout the project content output stage. First, the teacher collected the students' work (presentation outlines, poster drafts) and compiled a list of grammar points that students had problems with. Then, a worksheet with error correction exercises was prepared based on the problematic grammar points list. After students completed the exercises, they were given their drafts back, and they corrected their own mistakes. The task was done in groups and the teacher assisted the students as necessary.

\section{Mini Grammar Lessons}

This task was in general carried out in tandem with the error correction task. Based on the same list of problematic points, the teacher chose one grammar point and prepared a short (10 to 15 minutes) grammar lesson based on it. Following form and usage explanations, students completed worksheets with drill exercises meant to consolidate learning of the grammar point.

\section{Vocabulary Race}

This task was completed before reading a certain section of the book. The teacher compiled a list of keywords from the section, and prepared slips that contained only the meaning in context of the keywords. The slips were taped to the blackboard during the class, and the students were given the list of keywords. Students worked in pairs, with one student running to the board and trying to memorize one slip of paper, and then running back to dictate to the other student. After finishing half of the slips, the students swapped roles. When they finished writing down all the meanings, the pairs matched the list of keywords to their meanings. This was a contest, with the winners being the first pair to correctly match the meanings to the keywords.

\section{Vocabulary Notebooks}

Students were instructed to keep vocabulary notebooks as they read the novel, which included the target word, its part of speech, its meaning in context, and the Japanese translation. The vocabulary notebooks were used for various tasks, as students were asked to use words they had collected in the notebooks for preparing the discussion role sheets, for writing summaries of various sections of the novel, and for writing their predictions for the ending of the novel. 


\section{Appendix B}

\section{Student Impressions of the Child Soldiers Project}

Data on what the students felt they had gained throughout the Child Soldiers Project, as well as what difficulties they had experienced, was collected using the project end reflections sheet. Students answered the following:

1. List two things that you or your group did well during the project. Give reasons.

2. List two things that were difficult for you or your group during the project. Give reasons.

3. Write any other comments you have about the project.

Analysis of the student responses identified four areas students felt they made progress in: presentation skills, fluency, content learning, and group work skills. Below is a list of quotes from students. The quotes have not been modified from the students' original.

\section{Improved Presentation Skills}

Student A: "The presentation made me learn how to plan, show and talk about it. The experience can use when I grow up and had the same situation that I had to do a presentation about something."

Student B: "We could tell the audience by using pictures, numbers, gesture and slow speaking to heighten their understanding and interest."

\section{Improved Fluency}

Student C: "By poster session, I practiced to speak English. I speak more Japanese than English everyday because I never go to foreign countries. [...] For poster session, I read a lot of information in English, so my vocabulary grows up."

Student D: "We could do the presentation smoothly. Everyone presented their part with not so much miss. We could explain something that is not on the poster and answer the questions smoothly."

\section{Content Learning}

Student E: "I learned from the research many things that I don't know at that time."

Student F: "I learned so many things about war, child soldiers, UNICEF and our life that we cannot control by other people. Through this presentation my mind changed a lot."

\section{Group Work Skills}

Student G: "It was difficult to choose the topic of the presentation. Put everyone's opinion together is a really hard work, but it makes our presentation almost perfect, because more idea can come out."

Student $\mathrm{H}$ : "When we were making the posters, we discussed a lot so that's why we could make such a great poster. We all did our homework on time and we tried very hard."

On the other hand, students also reported problems with collaboration, as well as with making themselves understood to their audience. 


\section{Collaboration Issues}

Student I: "It was very hard to do work with other people, because everyone had different ideas and to make them one big idea we spend a lot of time."

\section{Audience Comprehension Issues}

Student J: "Getting audience's attention was very difficult because even though I made a pretty good hook, they couldn't understand what I was saying."

Student K: "Just saying or reading won't make people understand. By putting feelings, what I want to say would go into their heart." 